\title{
Energy-Efficient Lighting: Consumers' Perceptions and Behaviors
}

\author{
Nam-Kyu Park ${ }^{1} \&$ Eunsil Lee ${ }^{2}$ \\ ${ }^{1}$ Interior Design Department, University of Florida, Gainesville, FL, USA \\ ${ }^{2}$ School of Planning, Design \& Construction, Michigan State University, East Lansing, MI, USA \\ Correspondence: Nam-Kyu Park, Interior Design Department, College of Design, Construction and Planning, \\ University of Florida, 354 Arch building, Gainesville, FL 32611-5705, USA. Tel: 1-352-392-0252. E-mail: \\ npark@ufl.edu
}

Received: March 6, 2013

Accepted: April 8, 2013 Online Published: April 15, 2013

doi:10.5539/ijms.v5n3p26

URL: http://dx.doi.org/10.5539/ijms.v5n3p26

\begin{abstract}
The aim of the study was to identify consumers' perceptions of energy-efficient lighting in relation to their socio-demographic characteristics and the relationship of these perceptions to their behaviors of environmental lighting. A carefully designed questionnaire was sent to 2,000 randomly selected addresses in the Meridian Township area in Michigan. In total, 326 respondents returned a completed questionnaire, a response rate of $16.3 \%$. The questionnaire included three types of measures: energy-efficient lighting perceptions in general, perceptions of compact fluorescent lamps, and environmental lighting behaviors. Environmental lighting behaviors were measured in energy-efficient lighting usage behaviors and habitual behaviors.

The results indicate that there was a significant relationship between consumers' environmental lighting behaviors and lighting perceptions. The consumers who had more positive perceptions towards energy-efficient lighting were more likely to demonstrate the environmental lighting behaviors. The study also revealed some significant differences in consumers' lighting perceptions and behaviors in relation to socio-demographic characteristics. The findings of the study suggest that policy makers and lighting markets should implement new methods of promoting energy-efficient lighting more effectively and prevent generating further lighting misconceptions.
\end{abstract}

Keywords: energy-efficient lighting market, consumers' perceptions, consumers' environmental behaviors

\section{Introduction}

According to the U.S. Energy Information Administration (2012), electrical lighting consumes $23 \%$ of the energy used in commercial buildings, and an average household dedicates about $15 \%$ of its total electricity consumption to lighting. Although new lighting technologies can reduce energy required for lighting homes by 50 to $75 \%$, lighting consumption for homes increased from $9 \%$ of total consumption in 2001 to $15 \%$ in 2009 (U.S. Department of Energy, 2011). Household energy use is a major cause of air pollution and global warming, and $16 \%$ of U.S. greenhouse gas emissions derive from energy used in houses (U.S. Department of Energy, 2011).

Researchers and public advocates have encouraged the use of fluorescent lighting because it requires less electricity to operate than conventional lighting, and therefore uses less fossil fuel. Since fossil fuels are nonrenewable and emit harmful atmospheric pollutants, the use of fluorescent lighting has been cited not only as a means of saving energy, but also as a way to preserve the environment. The U.S. Department of Energy (2011) states that if every U.S. household replaced just one light bulb or fixture with an ENERGY STAR qualified one, the nation would save more than $\$ 600$ million each year in energy costs and prevent greenhouse gas emissions equivalent to what is produced by more than 800,000 cars.

During the past 20 years, many governmental agencies and utility companies have promoted the use of energy-efficient lighting, especially compact fluorescent lamps (CFL) for homes. Despite their efforts, consumer acceptance of energy-efficient technology in reference to residential lighting has been slow to develop. In the United States, the dominant light source in residential households is still the incandescent lamp using $89 \%$ of lighting energy in homes (U.S. Department of Energy, 2011). Therefore, encouraging energy-efficient lighting for residential applications is a critical component of today's utility management. 


\subsection{Purpose of the Study}

Given the current trend in terms of sustainability and the increasing level of concern in relation to conserving energy, it is important to understand why not all consumers are willing to accept energy-efficient lighting technology. Few studies have been conducted on this topic (Banwell, Brons, Freyssinier-Nova, Pizzo, \& Figueiro, 2004; Conway \& Mehra, 1998; Menanteau \& Lefebvre, 2000; Veitch \& Gifford, 1996). In addition, the relationships between perceptions and use of energy-efficient lighting among consumers have not yet been examined.

The purpose of this study is to identify consumers' perceptions of energy-efficient lighting in relation to their socio-demographic characteristics and the relationship of these perceptions to their behaviors of energy-efficient lighting in their homes. This research is therefore important in reference to improving the ways in which consumers conserve home energy through the use of lighting. The research questions are listed below:

What perceptions do consumers have about energy-efficient lighting?

What are consumers' environmental lighting behaviors at home?

How do consumers' lighting perceptions influence their environmental lighting behaviors at home?

\section{Literature Review}

Known as an energy-efficient lamp, the compact fluorescent lamp (CFL) was introduced in the beginning of the 1980s as an alternative to the incandescent lamps in the residential lighting market (Conway \& Mehra, 1998; Menanteau \& Lefebvre, 2000). With a screw base socket that fits a common incandescent lamp, CFLs operate on a quarter of the energy used by incandescent lamps to provide the same level of light, and last ten times longer. They are available in a variety of shapes and light colors to serve different lighting needs at home (DiLaura, Houser, Mistrick, \& Steffy, 2010; Winchip, 2008). Many lighting professionals and researchers suggest that consumers can enhance the appearance of their homes by utilizing current energy-efficient lighting systems (Banwell et al., 2004; Karlen \& Benya, 2004).

Nevertheless, domestic consumer acceptance of energy-efficient lighting has been slow to grow in the residential sector and the dominant light source in households is still the incandescent lamp in the United States (U.S. Department of Energy, 2011). Consumers are accustomed to the "warm" light of the incandescent lamps. These warm colors have been associated with a homey environment (Banwell at al., 2004). In contrast, the older fluorescent lighting was perceived as "cold" (Menanteau \& Lefebvre, 2000).

In identifying the barriers to the use of energy-efficient lighting systems, researchers have attributed resistance to consumers' limited knowledge of the benefits of energy-efficient lighting and a lack of awareness of recent aesthetic and technological advances (Banwell at al., 2004; Conway \& Mehra, 1998; Menanteau \& Lefebvre, 2000). Consumer responses to a study conducted by the Smithsonian Institution (2008) about energy-efficient lighting have confirmed these findings. Many consumers indicated that they are not aware of new lighting technologies or energy-efficient lighting. Some mentioned that consumers and/or consumers need to more education about the new lighting technologies in order to change their notions about lighting and convince them to adopt efficient lighting systems.

Banwell et al. (2004) and the U.S. Environmental Protection Agency (EPA) surveyed visitors about lighting who visited a designer showcase home. The visitors were asked to compare the energy efficient fluorescent lighting in the model home to the traditional incandescent lighting in a nearby comparable home. The results revealed that both random visitors and paid respondents rated the energy-efficient lighting as equivalent to or better than the incandescent lighting in color appearance, brightness, light distribution, appearance of people, visual comfort, visibility, flickering, and overall appearance of the home. Nearly $90 \%$ of the respondents said that they would like to have the energy-efficient fluorescent lighting in their homes. These results indicate that consumers want simpler information about new energy-efficient lighting technology (Veitch \& Gifford, 1996; Veitch, Hine, \& Gifford, 1993).

A study of energy-efficient lighting conducted by the Smithsonian Institution (2008) indicated that television programs, the Internet, advertisements and educational tools (research articles, consumer reviews, product information, brochures, and a college course) were some ways in which people learn about energy-efficient lighting. In addition, respondents mentioned the distribution of energy-efficient light lamps, personal recommendations, and promotions on energy efficiency by government agencies and utility companies.

Since the 1980s, studies of environmental beliefs, attitudes, and behaviors have become a major issue in environmental psychology research with interests in environmental conservation. Many studies have found that 
socio-demographic characteristics are related to environmental concerns and behaviors. Berger (1997) found that socioeconomic and demographic variables such as place of residence, types of house, educational achievement, and wealth play significant roles in reference to environmentally responsible behavior. Barr, Gilg, and Ford (2005) examined the characteristics of the typical "energy saver." Among their findings, the most committed to sustainable energy user groups were older, tended to own their home, lived in a terrace property. The most committed environmentalists have smaller households. According to Barr et al. (2005), non-environmentalists were more likely to be "younger, male, those with low incomes, who had received less formal education, and were less involved in the community."

Shen and Saijo (2008) examined the individual socio-demographic characteristics associated with environmental concerns in Shanghai, China. The results revealed that older respondents, male respondents, respondents with more education, and with higher incomes were more concerned about the environment and had more support for pro-environmental behavior than those who were less concerned. Household energy saving behavior, such as turning off lights in unoccupied rooms, is an example of a habitual action: "focused around everyday reductions in energy use that require either no or minimal structural adjustment" (Barr et al., 2005). Barr et al. (2005) emphasized that these energy-conserving behaviors are related to decisions that people make every day based on their previous experiences. Similarly, an on-going study by the Smithsonian Institution (2008) indicates that one's upbringing and personal experiences relating to events such as the energy crisis of the 1970s are believed to be some of the factors that influence lighting conservation behaviors.

\section{Methods}

\subsection{Sample and Data Collection}

The survey package was distributed by mail to a random selection of 2,000 household chosen from the telephone directory of the Meridian Charter Township, Ingham County, Michigan. In this study, only homeowners were included as home energy-saving behaviors were more affected with homeownership (Black, Sterm, \& Elworth, 1985). Respondents received the questionnaire, along with an introduction letter explaining the purpose of the study and instructions for completing the survey. A stamped, reply envelope was also included in the package. Respondents were asked to return the questionnaire within the following two weeks. A reminder was sent two weeks after the initial package to encourage respondents to complete and return the questionnaire if they had not already done so. A total of 326 were returned, representing a response rate of about $16.3 \%$. In total, 315 cases were retained for analysis since 11 cases had not been fully completed.

Prior to conducting the main survey, the research instrument was piloted using Robson's (2002) pretesting process. Thirty-five participants were recruited through convenience sampling, and each of these volunteers completed a questionnaire in the authors' presence, verbalizing all responses. The authors identified items that were consistently regarded as repetitive, misleading, or confusing, and they were revised accordingly. Prior to sending out the mail surveys, permission was granted by the University's Institutional Review Board Committee.

\subsection{Instrument}

The survey instrument was developed on the basis of previous studies about lighting perceptions and behaviors (Barr et al., 2005; Veitch \& Gifford, 1996) and a review of the Lighting Handbook published by the Illuminating Engineering Society of North American (DiLaura et al., 2010); that information was modified for the purposes of the present study. The participants' general perceptions of energy-efficient lighting were measured by their beliefs and attitudes about energy-saving practices at home and their environmental awareness of lighting issues. Participants were asked to evaluate the extent to which they agreed with statements such as "Using energy-efficient lighting at home is an important way to conserve energy" and "Government and utility companies should raise our awareness of environmental issues on lighting." Each item was rated on a 7-point rating scale from 1 (strongly disagree) to 7 (strongly agree).

Consumers' perceptions about compact fluorescent lamps (CFL) were addressed in terms of five variables: visual comfort, aesthetics, impression, cost, and technological attribute. First, consumers' perceptions about the visual comfort of CFLs were measured in reference to four items: glaring/not glaring, tense/relaxing, irritating/soothing, uncomfortable/comfortable. Second, the aesthetics of CFL were measured through the use of three items: unpleasant/pleasant, unattractive/attractive, and ugly/beautiful. A seven-point bi-polar scale was used to evaluate the perceptions of visual comfort and the aesthetics of CFL.

The last three measurements, impression, cost, and the technological attribute of CFL were evaluated using a seven-point Likert-type scale from 1 (strongly disagree) to 7 (strongly agree). Impressions of CFL were measured via two items: "Compact fluorescent lamp make the home look bad" and "Compact fluorescent lamp 
make people look awful." Consumers' perceptions about the cost of CFL were measured through the use of one item with the statement "Compact fluorescent lamps are costly to buy." The perceptions about technological attribute of CFL were measured via four items which asked about slow start-up time, flickering, and incompatibility with common light fixtures.

The questions about consumers' energy-efficient lighting behaviors consisted of two items: energy-efficient lighting usage behaviors and habitual behaviors. The questions were selected and modified from studies conducted by Poortinga, Steg, and Vlek (2004) and Barr et al., (2005). Questions about energy-efficient lighting usage behaviors inquired about respondents' efforts and commitment to buy energy-efficient lighting rather than other types and how much energy-efficient lighting is utilized in their homes. Habitual behaviors were defined as "activities focused around everyday reductions in energy use that require either no or minimal structural adjustment" (Barr et al., 2005). Using a seven-point Likert-type scale, participants were asked to rate the extent to which they agreed with statements such as "As I leave the room, I make sure that I turn off the light switch."

The last section of the questionnaire inquired about socio-demographic information in relation to the participants. Links between socio-demographic characteristics and environmental attitude and behavior have been studied by several researchers (Berger, 1997; Shen \& Saijo, 2008; Xiao \& McCright, 2007). Referring those previous studies, the questions about socio-demographic characteristics of the respondents included gender, age, education level, annual household income, and house size.

To test the internal consistency of scales measuring variables, Cronbach's alpha coefficients were calculated. Alpha values for internal consistency were 0.70 for the general perception of energy-efficient lighting measure, 0.77 for the visual comfort of CFL, 0.80 for the aesthetics of CFL, 0.72 for the impression on CFL, 0.66 for the technological attribute of CFL, 0.83 for the energy-efficient lighting usage behavior, and 0.87 for the habitual behavior measure. Because each of these alpha levels is above the acceptable threshold $(0.60)$ for reliability (Nunnaly \& Bernstein, 1994), all these measures were retained for further analysis.

\section{Results}

\subsection{Characteristics of Respondents}

Table 1 presents the frequency and percentage distributions for personal and contextual characteristics of the consumers: gender, age, education, household income, and house size. The sample consisted of females $56.5 \%$ (n $=178)$ and males $41.0 \%(n=129)$. Seventeen percent of respondents were above 65 years old and about one-third $(32.7 \%)$ were in the 55- to 64-year-old range. An additional third $(29.2 \%)$ were in the 45 - to 54 -year-old range, while $21 \%$ of respondents were in the 25 - to 44 -year-old range.

In terms of education, over half $(53 \%)$ of respondents had graduate or professional degrees. Thirty percent of the participants were college graduates and another $12.7 \%$ of respondents had at least a high school diploma. The majority of respondents were in two income categories: about half of the respondents (47.6\%) earned "more than $\$ 100,000$ " and about one third (32.1\%) of respondents earned " 50,000 to $\$ 99,999$ " annually. Slightly less than $40 \%$ of respondents lived in houses of 2000 sq.ft. $(185.8 \mathrm{~m} 2)$ or less. Slightly more than $40 \%$ of respondents lived in 2,001 - 3,000 sq.ft. (185.9 - $278.7 \mathrm{~m} 2)$ homes. Nineteen percent of respondents lived in houses that are 3000 sq.ft. $(278.7 \mathrm{~m} 2)$ or more.

In total, most of socio-demographic characteristics of the samples were similar to those provided by U.S. Census Bureau (2010). This indicates that the samples selected from the Meridian Charter Township, Ingham County, Michigan well represent the characteristics of the general U.S. population. However, the income and educational levels of the respondents were considerably higher than the $\$ 52,029$ of median household income and the $24.4 \%$ of people who have bachelor's degree or higher in the United States (U.S. Census Bureau, 2010). Although this study used systematic random sampling to distribute mail surveys, the samples had a higher income and more education. 
Table 1. Percentage distribution of respondents' characteristics

\begin{tabular}{llll}
\hline Respondents' Characteristics & Frequency & $\%$ \\
\hline Gender & Male & 129 & 41.0 \\
& Female & 178 & 56.5 \\
Age & Total & 307 & 100 \\
& $25-44$ years & 66 & 21.0 \\
& $45-54$ years & 92 & 29.2 \\
& $55-64$ years & 103 & 32.7 \\
& 65 years and over & 54 & 17.1 \\
Educational level & Total & 315 & 100 \\
& High school/GED/some college & 40 & 12.7 \\
& Bachelor's degree & 106 & 33.7 \\
& Graduate or professional degree & 167 & 53.0 \\
Income level & Total & 315 & 99.4 \\
& \$4,999 or less & 37 & 11.7 \\
& \$50,000-99,999 & 101 & 32.1 \\
House size & \$100,000 or more & 150 & 47.6 \\
& Total & 288 & 100 \\
& 2,000 sq.ft. or less & 122 & 38.7 \\
& 2,001 - 3,000 sq.ft. & 128 & 40.6 \\
& 3000 sq.ft or more & 60 & 19.0 \\
& Total & 315 & 100 \\
\hline
\end{tabular}

Note: The numbers vary due to missing responses.

\subsection{Consumers' Perceptions about Energy-Efficient Lighting}

Consumers' perceptions about energy-efficient lighting were evaluated in regard to the general perception of energy-efficient lighting, and to perceptions about specific attributes of compact fluorescent lighting (visual comfort, aesthetics, impression, cost, and technology). The results showed that house size was statistically significant $[\mathrm{F}(2,302)=3.87, \mathrm{p}<.05]$. Respondents who owned a smaller house $(\mathrm{M}=5.26, \mathrm{SD}=1.04)$ had a more positive perception on energy-efficient lighting in general than respondents whose house was between 2,001 and 3,000 sq.ft. $(\mathrm{M}=4.93, \mathrm{SD}=1.06)$ and respondents whose house was more than 3000 sq.ft. $(\mathrm{M}=4.89$, $\mathrm{SD}=1.14)$.

In addition, consumers' perceptions about compact fluorescent lighting (CFL) were examined. Significant differences were found in terms of gender $[\mathrm{t}(301)=3.29, \mathrm{p}<.01]$ and age $[\mathrm{F}(3,307)=2.99, \mathrm{p}<.05]$. The results indicated that males $(\mathrm{M}=4.21, \mathrm{SD}=.83)$ rated more positively on the visual comfort of CFL than females $(\mathrm{M}=$ $3.87, \mathrm{SD}=.97)$ did. Among four age groups, respondents, 65 years and over $(\mathrm{M}=4.28, \mathrm{SD}=.70)$ showed more positive perception about the visual comfort of CFL than did respondents between 25 and 44 years old $(\mathrm{M}=3.93$, $\mathrm{SD}=.99)$, and between 45 and 54 years old $(\mathrm{M}=3.85, \mathrm{SD}=.85)$; this perception was not found among respondents between 55 and $64(\mathrm{M}=4.09, \mathrm{SD}=1.00)$.

As for the aesthetic aspect of CFL, gender $[\mathrm{t}(301)=2.88, \mathrm{p}<.01]$ was the only variable that showed a statistically significant difference. Male respondents $(\mathrm{M}=3.97, \mathrm{SD}=1.01)$ rated significantly higher on the aesthetics of CFL than female respondents $(\mathrm{M}=3.59, \mathrm{SD}=1.19)$ did. The impression of CFL had a significant difference in gender $[\mathrm{t}(303)=3.57, \mathrm{p}<.01]$. Male $(\mathrm{M}=4.80, \mathrm{SD}=1.38)$ respondents showed more positive impressions on $\mathrm{CFL}$ than female $(\mathrm{M}=4.22, \mathrm{SD}=1.41)$ respondents did.

When the respondents were asked to evaluate their perception about cost to buy CFL, gender $[t(303)=-2.19, p$ $<.05]$ was the only variable that showed a statistically significant difference. Female respondents $(\mathrm{M}=3.10, \mathrm{SD}$ $=1.54)$ perceived the compact fluorescent lamps as more costly than did male respondents $(\mathrm{M}=2.74, \mathrm{SD}=$ 1.29). For the technological attribute of CFL, gender $[\mathrm{t}(303)=2.92, \mathrm{p}<.01]$ was also statistically significant. Male $(\mathrm{M}=4.35, \mathrm{SD}=1.13)$ respondents more positively perceived the technological attribute of $\mathrm{CFL}$ than female $(\mathrm{M}=3.96, \mathrm{SD}=1.15)$ respondents did.

\subsection{Consumers' Environmental Lighting Behaviors}

Respondents' environmental lighting behaviors at home were investigated in relation to energy-efficient lighting usage behavior and habitual behavior. Energy-efficient lighting usage behavior was significantly different in income level $[\mathrm{F}(2,285)=3.35, \mathrm{p}<.05]$. Those in the highest $(\mathrm{M}=4.71, \mathrm{SD}=1.42)$ income category (more than $\$ 100,000)$ rated significantly lower on buying and using energy-efficient lighting for their homes than those in 
the lower $(\mathrm{M}=5.23, \mathrm{SD}=1.62)$ and medium $(\mathrm{M}=5.10, \mathrm{SD}=1.38)$ income categories.

Regarding the habitual behavior, there were statistical significant differences on two variables: gender [t(302) = $-2.51, \mathrm{p}<.05]$ and income level $[\mathrm{F}(2,283)=3.39, \mathrm{p}<.05]$. Respondents whose income fell in the mid-range $(\mathrm{M}$ $=5.97, \mathrm{SD}=1.09$ ) rated significantly higher on their habitual energy-saving behaviors than other respondents whose income was under $\$ 49,999(\mathrm{M}=5.46, \mathrm{SD}=1.56)$ and more than $\$ 100,000(\mathrm{M}=5.56, \mathrm{SD}=1.45)$. In terms of gender, female respondents $(\mathrm{M}=5.82, \mathrm{SD}=1.27)$ exhibited significantly higher energy saving behaviors than did male respondents $(\mathrm{M}=5.42, \mathrm{SD}=1.48)$.

\subsection{Relationships between Lighting Perceptions and Environmental Lighting Behaviors}

Two regression analyses were conducted to examine the relationship between consumers' perceptions about energy-efficient lighting and their environmental lighting behaviors. Table 2 shows that energy-efficient lighting usage and habitual behaviors were regressed on the perception variables. These variables could explain $27 \%$ of usage behaviors and $6 \%$ of habitual behaviors. Two variables of lighting perceptions were significantly associated with energy-efficient lighting usage behavior: general perception of energy-efficient lighting $(\beta=$ 0.393, $\mathrm{p}<.01)$ and impression on $\operatorname{CFL}(\beta=0.233, \mathrm{p}<.01)$. The results indicated that the more positive perceptions the respondents showed about energy-efficient lighting in general and impression on CFL, the more the respondents tended to purchase and utilize energy-efficient lighting for their homes.

Table 2. Standardized regression coefficients for energy-efficient lighting behaviors

\begin{tabular}{|c|c|c|c|c|}
\hline \multirow[b]{2}{*}{ Variables } & \multicolumn{2}{|c|}{ Usage behaviors } & \multicolumn{2}{|c|}{ Habitual behaviors } \\
\hline & $\beta$ & t-value & $\beta$ & t-value \\
\hline $\begin{array}{l}\text { General perception of energy-efficient } \\
\text { lighting }\end{array}$ & .393 & $7.355 * *$ & .176 & $2.906 * *$ \\
\hline Visual comfort of CFL & -.046 & -.692 & -.045 & -.590 \\
\hline Aesthetics of CFL & .031 & .438 & .014 & .181 \\
\hline Impression on CFL & .233 & $3.343 * *$ & .041 & .523 \\
\hline Cost of CFL & .026 & .493 & -.002 & -.032 \\
\hline Technological attributes of CFL & .017 & .276 & .143 & $2.007 *$ \\
\hline R2 & .282 & & .074 & \\
\hline Adj. R2 & .268 & & .055 & \\
\hline
\end{tabular}

$* \mathrm{p}<.05 ; * * \mathrm{p}<.01$

As shown in Table 2, two variables are strongly associated with lighting habitual behaviors: general perception of energy-efficient lighting $(\beta=0.176, \mathrm{p}<.01)$ and technological attribute of CFL $(\beta=0.143, \mathrm{p}<.01)$. Both variables showed a significantly positive relationship with energy-efficient lighting habitual behaviors. The results indicated that the more positive perceptions the respondents showed about energy-efficient lighting in general and technological attribute of CFL, the more likely the respondents were to practice lighting energy-saving activities in their homes.

\section{Discussion}

In order to encourage energy efficient lighting choices, this study was conducted to ascertain consumers' underlying perceptions of energy-efficient lighting with particular emphasis on the socio-demographic characteristics of consumers for their environmental lighting behaviors at home. The findings of this study yield strong support that the socio-demographic characteristics of consumers are related to perceptions of energy efficient lighting and environmental lighting behaviors and consumers' lighting perceptions influence their environmental lighting behaviors.

Findings of the consumers' general perception of energy-efficient lighting showed significant differences in house size. Respondents who owned a larger house (more than 3,000 sq. ft.) were more willing and likely to accept energy-efficient lighting for their homes. As previous studies have shown, household energy concern and use were correlated with household size (Poortinga et al., 2004). As a new finding of this study, home lighting energy use may be related to house size. Perhaps, people live in a bigger house consume more energy and pay more for it. Thus, knowing the benefit of energy-efficient lighting, consumers living in larger house may want to cut energy use and increase energy efficiency.

Addressing five variables of visual comfort, aesthetics, impression, cost, and technological attributes, consumers' 
perceptions about compact fluorescent lighting were examined on the characteristics of consumers. When introduced on the residential market, the compact fluorescent lighting faced numerous barriers (Menanteau \& Lefebvre, 2000). Those five characteristics of are known as adoption barriers (Banwell at al., 2004; Conway \& Mehra, 1998; Menanteau \& Lefebvre, 2000), yet no study has examined them in relation to the socio-demographic characteristics of consumers.

In all five attributes of CFL, the gender effect was significant. Male respondents perceived the attributes of CFL more positively than female respondents. In terms of environmentally significant attitudes and behaviors, studies show repeated and significant differences between men and women. Women in the U.S. are more environmentally significant than men (Dietz, Kalof, \& Stern, 2002; Hunter, Hatch, \& Johnson, 2004; Zelezny, Chua, \& Aldrich, 2000). In line with earlier studies, female respondents were expected to be more favorable to CFL considering environmental concerns and impacts. However, as far as lighting issues with visual comfort, aesthetics, and impression at home, females may think compact fluorescent lamps are not suitable for their home; studies have shown that women's negative mood decreased in the warm light source (Knez, 1995) and consumers in the U.S. has negative impressions of fluorescent lighting as a cold light source (Banwell et al., 2004; Menanteau \& Lefebvre, 2000).

The current findings imply that males may be more aware of advanced CFL technologies such as better light output and availability of different light colors. Female respondents were more cost-conscious, perceiving the cost of the compact fluorescent lamps as higher than male respondents did. Higher cost of CFLs compare to incandescent lamps was known as a major constraint to adoption (Conway \& Mehra, 1998; Menanteau \& Lefebvre, 2000). Although the cost of new CFL technology is significantly lower now than it was in the past, female consumers' perception on the cost of CFL was more negative than that of male consumers.

In this study, the oldest respondents (65 years and over) were more positive about the CFL's visual comfort than younger respondents were. Due to elderly people's sensitivity to glare and the yellowing of the lens, a lighting environment for elderly people should fall within the bluish-white color temperature range (Winchip, 2008). Although fluorescent lighting has been perceived as too "cold" for domestic comfort (Menanteau \& Lefebvre, 2000), this association might provide better visual comfort for the elderly. Future research should examine the effects of the different ranges of color temperature for CFLs on visual comfort in home environments considering people with different ages.

To understand consumers' environmental lighting behaviors, energy-efficient lighting usage behavior and habitual behavior were analyzed. In terms of the energy-efficient lighting usage behavior, consumers' income had statistical significance. Respondents in the lowest income categories $(\$ 49,999$ or less) showed the highest energy-efficient lighting usage behavior. This finding was different from previous studies, where households with higher income were found to be positively associated with environmental concern (Xiao \& McCright, 2007) and more engaged in pro-environmental behaviors (Clark, Kotchen, \& Moore, 2003). Additionally, higher-income end users were more willing to practice energy-efficient lighting behavior since energy-efficient lighting behaviors often require long-term financial and time commitments (Menanteau \& Lefebvre, 2000). The result of the current study may imply that lower-income households may be more sensitive to energy costs. Despite buying energy-efficient lighting products to save home energy, this behavior may not reflect concern for the environmental benefits. Hence, it might be interesting to study how frugal consumers' use of energy-efficient lighting system is related to their environmental attitudes and practices.

In terms of habitual behavior, income level and gender revealed significant differences. Respondents earning $\$ 50,000$ to $\$ 99,999$ and females rated significantly higher on their habitual energy-saving behaviors than did male respondents and those earning less than $\$ 49,999$ and more than $\$ 100,000$. Regarding gender effect on habitual energy-saving behaviors, the result corresponds to the previous studies, indicating that women are more environmentally significant than men (Hayes, 2001; Zelezny et al., 2000). According to some earlier research, people with higher income are expected to exhibit higher environmental attitudes and behaviors (Gatersleben, Steg, \& Vlek, 2002; Inglehart, 1995). Yet other studies suggest that weak associations between household income and environmental concern (Brechin \& Kempton, 1997; Göksen, Adaman, \& Zenginobuz, 2002). The result of this study indicates that household income is associated with environmental habitual behavior through use of lighting. In addition, consumers in the mid income range conserve energy through their daily use of lighting in their homes.

The findings showed that energy-efficient lighting usage behaviors, such as purchasing environmentally significant lighting products and utilizing more efficient lighting systems for their homes, were significantly related to perceptions of energy-efficient lighting, including impression of CFL. As anticipated, energy-efficient 
lighting usage behaviors were found to be positively related to general perception of energy-efficient lighting. More than any other attributes of CFLs, the impression of CFL was highly predictive of energy-efficient lighting usage behaviors at home. In terms of habitual behavior, the results demonstrated that the more positive perceptions consumers had towards energy-efficient lighting in relation to environmental concern, the more likely the respondents were to practice habitual energy-saving activities for their homes. In addition, only the technology of CFL was predictive for habitual light conservation behaviors. The present study demonstrated that consumers' environmental lighting behaviors were significantly associated with their underlying perceptions of energy-efficient lighting. The findings clearly showed that respondents, who perceived the energy-efficient lighting to be more positive, would be more likely to buy and utilize energy-efficient lighting for their homes and demonstrate habitual energy-saving behaviors in their daily life.

From the socio-demographic standpoint, the present study revealed some significant findings in consumers' energy-efficient lighting perceptions and environmental lighting behaviors. First, there was a clear gender difference. It was interesting to note that females practiced more habitual energy-saving activities at home than males although they perceived energy-efficient lighting more negatively than males. Males tended to be more positive about all five attributes of compact fluorescent lamps. These inconsistent findings of gender effect between lighting perception and practice may be related to the norm, which environmentally significant attitudes are not necessarily followed by environmentally significant behavior (Dietz et al., 2002; Poortinga et al., 2004; Ignatow, 2006).

Second, annual household incomes were related to significant differences in energy-efficient usage behaviors and habitual behaviors. The members of the mid-range income group showed the highest higher habitual energy-saving activities. In contrast, the lowest income group purchased and used more energy-efficient lighting systems for their homes. This evidence suggests that income is not predictive of environmental behavior in terms of conserving energy through lighting. Concerning the relationship between household income and environmental attitudes and behaviors, the findings of many previous studies are mixed (Howell \& Laska, 1992).

This study has several implications. As demonstrated in the present study, policy makers and lighting markets should implement new methods of promoting energy-efficient lighting more effectively and prevent generating further lighting misconceptions. Marketing strategies that promote the use of energy-efficient lighting can be designed to highlight areas that most interest males and females since gender affects respondents' energy-efficient lighting perception and their behaviors. For example, males showed more positive perceptions toward CFL than did females. The professionals may reinforce positive aspects of the energy-efficient lighting to their female clients and offer updated technological insights. Furthermore, stakeholders in lighting industry still need to promote the benefits of energy-efficient lighting. It is important for government and lighting industry to publicize new lighting technologies and prevent further misconceptions that affect lighting behaviors (Veitch et al., 1993).

The educational background of the respondents was highly skewed although a systematic random sampling method was utilized for this study. With this high survey response rate from consumers with a higher level of education in the Meridian Township of Michigan, this study shows that people with a higher education are more environmentally significant (Engel \& Plötschke, 1998; Ignatow, 2006; Scott \& Willits, 1994). However, the findings of the study should be cautiously applied to consumers elsewhere. Conducting future research, this study should be replicated with samples from other areas that represent normal distributions of demographic factors, particularly educational and income levels.

\section{References}

Banwell, P., Brons, J., Freyssinier-Nova, J. P., Pizzo, P., \& Figueiro, M. (2004). A demonstration of energy-efficient lighting in residential new construction. Lighting Research and Technology, 36, 147-164. http://dx.doi.org/10.1191/1365782804li110oa

Barr, S., Gilg, A. W., \& Ford, N. (2005). The household energy gap: examining the divide between habitual- and

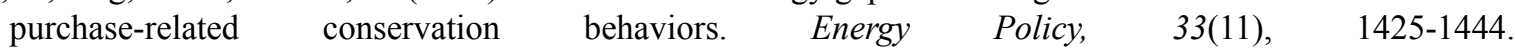
http://dx.doi.org/10.1016/j.enpol.2003.12.016

Berger, I. E. (1997). The demographics of recycling and structure of environmental behavior. Environment and Behavior, 29(4), 515-531. http://dx.doi.org/10.1177/001391659702900404

Black, J. S., Sterm, P., \& Elworth, J. T. (1985). Personal and contextual influences on household energy adaption. Journal of Applied Psychology, 70(1), 3-21. http://dx.doi.org/10.1037/0021-9010.70.1.3

Brechin, S., \& Kempton, W. (1997). Beyond postmaterialist values: National versus individual explanations of 
global environmentalism. Social Science Quarterly, 78(1), 16-23.

Clark, C. F., Kotchen, M. J., \& Moore, M. R. (2003). Internal and external influences on pro-environmental behavior: Participation in a green electricity program. Journal of Environmental Psychology, 23(3), 237-246. http://dx.doi.org/10.1016/S0272-4944(02)00105-6

Conway, K. M., \& Mehra, M. (1998). Lighting market opportunities: Reconciling consumers' purchasing behaviors with environmental values. Journal of Illuminating Engineering Society, 27(2), 67-76.

Dietz, T., Kalof, L., \& Stern, P. C. (2002). Gender, values, and environmentalism. Social Science Quarterly, 83, 353-364. http://dx.doi.org/10.1111/1540-6237.00088

DiLaura, D., Houser, K., Mistrick, R., \& Steffy G. (Eds.). (2010). The IESNA lighting handbook (10th ed.). New York: Illuminating Engineering Society of North America Publications Department.

Engel, U., \& Plötschke, M. (1998). Willingness to pay for the environment: Social structure, value orientations and environmental behavior in a multilevel perspective. Innovation, 1(3), 315-332. http://dx.doi.org/10.1080/13511610.1998.9968571

Gatersleben, B., Steg, L., \& Vlek, C. (2002). The measurement and determinants of environmentally significant

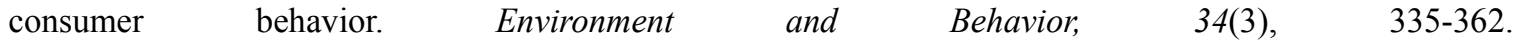
http://dx.doi.org/10.1177/0013916502034003004

Göksen, F., Adaman, F., \& Zenginobuz, E. Ü. (2002). On environmental concern, willingness to pay, and postmaterialist values: Evidence from Istanbul. Environment \& Behavior, 34(5), 616-633. http://dx.doi.org/10.1177/0013916502034005003

Hayes, B. C. (2001). Gender, scientific knowledge, and attitudes toward the environment: A cross-national analysis. Political Research Quarterly, 54(3), 657-671. http://dx.doi.org/10.1177/106591290105400309

Howell, S. E., \& Laska, S. B. (1992). The changing face of the environmental coalition: A research note. Environment and Behavior, 24(1), 134-144. http://dx.doi.org/10.1177/0013916592241006

Hunter, L., Hatch, A., \& Johnson, A. (2004). Cross-national gender variation in environmental behaviors. Social Science Quarterly, 85(3), 677-694. http://dx.doi.org/10.1111/j.0038-4941.2004.00239.x

Ignatow, G. (2006). Cultural models of nature and society: Reconsidering Environmental attitudes and concern. Environment and Behavior, 38(4), 441-461. http://dx.doi.org/10.1177/0013916505280791

Inglehart, R. (1995). Public support for environmental protection: Objective problems and subjective values in 43 societies. Political Science and Politics, 28(1), 57-72. http://dx.doi.org/10.2307/420583

Karlen, M., \& Benya, J. (2004). Lighting design basics. New Jersey: John Wiley \& Sons, INC.

Knez, I. (1995). Effects of indoor lighting on mood and cognition. Journal of Environmental Psychology, 15(1), 39-51. http://dx.doi.org/10.1016/0272-4944(95)90013-6 begin_of_the_skype_highlighting

Menanteau, P., \& Lefebvre, H. (2000). Competing technologies and the diffusion of innovations: the emergence of energy-efficient lamps in the residential sector. Research Policy, 29(3), 375-389. http://dx.doi.org/10.1016/S0048-7333(99)00038-4

Nunnaly, J., \& Bernstein, I. (1994). Psychometric theory (4th ed.). New York: McGraw-Hill.

Poortinga, W., Steg, L., \& Vlek, C. (2004). Values, environmental concern, and environmental behavior: A study into household energy use. Environment and Behavior, 36(1), 70-92. http://dx.doi.org/10.1177/0013916503251466

Robson, C. (2002). Real World Research. Oxford, UK: Blackwell.

Scott, D., \& Willits, F. (1994). Environmental attitude and behavior: A Pennsylvania survey. Environment and Behavior, 26(2), 239-260. http://dx.doi.org/10.1177/001391659402600206

Shen, J., \& Saijo, T. (2008). Reexamining the relations between socio-demographic characteristics and individual environmental concern: Evidence from Shanghai data. Journal of Environmental Psychology, 28(1), 42-50. http://dx.doi.org/10.1016/j.jenvp.2007.10.003

Smithonian Institution. (2008). Lighting the way: collecting history with World Wide Web. Retrieved from http://americanhistory.si.edu/lightproject/introduction/intro.htm

U.S. Census Bureau. (2010). 2010 Census: Michigan Profile. Retrieved from http://www.census.gov/geo/www/guidestloc/pdf/26_Michigan.pdf 


\section{U.S. Department of Energy. (2011). CFL market profile. Retrieved from http://www.energystar.gov/ia/products/downloads/CFL_Market_Profile.pdf}

U.S. Energy Information Administration. (2012). How much electricity is used for lighting in the United States? Retrieved from http://www.eia.doe.gov/tools/faqs/faq.cfm?id=99\&t=3

Veitch, J. A., \& Gifford, R. (1996). Assessing beliefs about lighting effects on health, performance, mood, and social behavior. Environment and Behavior, 28(4), 446-470. http://dx.doi.org/10.1177/0013916596284002

Veitch, J. A., Hine, D. W., \& Gifford, R. (1993). End users' knowledge, beliefs, and preferences for lighting. Journal of Interior Design, 19(2), 15-26. http://dx.doi.org/10.1111/j.1939-1668.1993.tb00159.x

Winchip, S. M. (2008). Fundamentals of lighting. New York: Fairchild Publications, Inc.

Xiao, C., \& McCright, A. M. (2007). Environmental concern and sociodemographic variables: A study of statistical models. Journal of Environmental Education, 38(2), 3-13. http://dx.doi.org/10.3200/JOEE.38.1.3-14

Zelezny, L. C., Chua, P., \& Aldrich, C. (2000). Elaborating on gender differences in environmentalism. Journal of Social Issues, 56(3), 443-457. http://dx.doi.org/10.1111/0022-4537.00177 